\title{
O GOVERNO DA INSEGURANÇA NAS CIDADES BRASILEIRAS CONTEMPORÂNEAS: UM EXERCÍCIO DE ANÁLISE À LUZ DAS CONTRIBUIÇÕES DE MICHEL FOUCAULT SOBRE OS PODERES E SUAS ESPACIALIDADES
}

\section{THE GOVERNMENT OF INSECURITY IN CONTEMPORARY BRAZILIAN CITIES: AN EXERCISE OF ANALYSIS IN THE LIGHT OF MICHEL FOUCAULT'S CONTRIBUTIONS ON THE POWERS AND THEIR SPACIALITIES}

Iafet Leonardi BRICALLI ${ }^{1}$

\begin{abstract}
Resumo: O presente texto propõe-se a afirmar a importância de Michel Foucault para a análise geográfica. À luz de uma releitura da periodização das formas de se exercer o poder na sociedade ocidental e de suas respectivas espacialidades estabelecida por Foucault, realiza-se um exercício de análise das formas com que as cidades brasileiras contemporâneas se organizam como resposta aos riscos e inseguranças. Busca-se, assim, observar em que medida aspectos da soberania, da disciplina e da biopolítica estão atualizados na atuação do Estado brasileiro e da iniciativa privada em diferentes frentes, tais como a atuação da polícia militar sobre os espaços habitados pelas pessoas mais pobres, a política de encarceramento em massa conduzida pelo Estado brasileiro, a expansão de condomínios fechados e a utilização de câmeras de vigilância em espaços públicos.
\end{abstract}

Palavras-chave: Michel Foucault - Poder - Espaço - Insegurança

\begin{abstract}
The present text proposes to affirm the importance of Michel Foucault for the geographic analysis. In light of a re-reading of the ways in which power is exercised in Western society and its spatiality established by Foucault, na exercise is performed to analyze the ways in which Brazilian contemporary cities are organized in response to risks and insecurities. It seeks to observe the extent to which aspects of sovereignty, discipline and biopolitics are updated in the Brazilian state and private initiative on different fronts, such as the military Police action on the spaces in habited by the poorest people, the policy of mass in carceration conducted by the Brazilian State, the expansion of gated communities and the use of surveillance cameras in public spaces.
\end{abstract}

Keywords: Michel Foucault - Power - Space - Insecurity

\section{Introdução}

Em uma conhecida entrevista, questionado sobre o lugar da geografia em sua arqueologia do saber, Michel Foucault (FOUCAULT, 2008a, p. 154) respondeu que este papel deveria caber aos próprios geógrafos, uma vez que seria impossível para ele tomar todas as ciências, todos os conhecimentos e todos os domínios do saber de que alguma maneira ele estava próximo e fazer as suas respectivas arqueologias.

A provocação do entrevistador pauta-se na proximidade que Foucault sempre teve em relação à geografia, considerando que a sua obra "toca" o espaço em diferentes momentos. Assim, seja metaforicamente ou não, Foucault utiliza-se de diversas noções e conceitos

\footnotetext{
${ }^{1}$ Mestre em Geografia pela Universidade Federal do Espírito Santo (UFES). Atualmente édoutorando em Ciências Sociais pela Universitàdegli Studi di Genova (Itália). E-mail: iafet.leonardibricalli@edu.unige.it
} 
próprios da geografia ou por ela utilizados: posição, deslocamento, espaço, lugar, território, arquipélago, geopolítica, regiões, paisagem, etc. Mesmo assim, e ao contrário do que acontece em outros países, a aproximação entre Foucault e a geografia é ainda pouco verificada no Brasil, o que resulta em raras pesquisas que tomem por referência o trabalho do filósofo. Como diz Haesbaert (2008) no título de sua resenha para a tradução do livro de Foucault Segurança, Território, População, Foucault continua provocando os geógrafos. E, acrescentaríamos nós, principalmente os brasileiros.

De modo a prestar uma contribuição para a relação entre Foucault e a geografia brasileira e, principalmente, para suscitar futuras pesquisas empíricas que levem adiante esse projeto, é que este texto foi escrito. Pretende-se fazer uma releitura das formas com que, segundo Foucault, a sociedade ocidental encontrou para exercer o poder de acordo com cada contexto histórico. Para a geografia, o que é ainda mais importante é que a cada forma de se exercer o poder corresponde uma espacialidade. Como o método genealógico de Foucault é uma maneira de se recorrer ao passado para se entender o presente (a história do presente), isso significa dizer que as características de exercício do poder de cada um dos períodos históricos indicados por Foucault estão presentes nas sociedades atuais e nos espaços por elas habitados.

Assim sendo, faremos um exercício de análise de modo a compreender de que maneira a sociedade e o espaço, no Brasil, guardam resquícios das relações que Foucault estabelece entre o poder e o espaço. Nos concentraremos fundamentalmente na maneira como as cidades brasileiras estão sendo organizadas em torno da administração dos riscos que uma complexificação social e urbana impõem à sociedade, considerando quatro frentes de atuação do Estado e da iniciativa privada que, acreditamos, guardam aproximações com as análises de Foucault: a atuação da polícia militar no controle dos espaços habitados pela população pobre brasileira, a política de encarceramento em massa levada a cabo pelo Estado brasileiro, a expansão de condomínios fechados e o uso de câmeras de vigilância nos espaços públicos.

Nas nossas análises, tomamos o devido cuidado para não forçar uma relação direta entre as análises de Foucault, que dizem respeito ao Ocidente em geral, mas são mais aplicáveis à realidade europeia, principalmente a francesa, e a realidade brasileira, para evitar que as ideias estejam fora de lugar. Mas o Brasil, apesar de sua formação social particular, guarda fortes resquícios das sociedades europeias e suas instituições, o que nos permite fazer esse exercício que nos propomos, sem deixar de fazer as devidas relativizações quando necessário.

\section{O poder e o espaço segundo Michel Foucault: soberania, disciplina e biopolítica (ou segurança)}

A soberania (a partir da Idade Média), a disciplina (a partir do século XVIII) e a biopolítica $^{2}$ (a partir do século XIX) é a periodização que Foucault (2008d) estabelece a respeito das modalidades de poder que a sociedade europeia, particularmente a francesa, encontrou, a partir da Idade Média, para manter os desvios, transgressões e criminalidades dentro de limites que fossem social e economicamente aceitáveis.

As modalidades de poder não aparecem dissociadas, o que muda é apenas o "dominante" em cada contexto histórico e geográfico. Não haveria, assim, uma era da

\footnotetext{
${ }^{2}$ Foucault ora fala de biopolítica, ora de segurança, ora de governamentalidade. De acordo com a nossa interpretação, a biopolítica seria a denominação de uma estratégia de poder específica, uma forma de poder de governo sobre os outros, que se exerce a partir de mecanismos de segurança. No decorrer do texto, utilizamos ora o termo biopolítica, ora o termo segurança de acordo com a exigência de cada situação.
} 
soberania, outra da disciplina e outra ainda da biopolítica. São as técnicas que vão se aperfeiçoando e encontrando novas maneiras de exercer o poder. Segundo o próprio Foucault:

[...] basta ver o conjunto legislativo, as obrigações disciplinares que os mecanismos de segurança modernos incluem, para ver que não há sucessão: lei, depois disciplina, depois segurança. A segurança é uma certa maneira de acrescentar, de fazer funcionar, além dos mecanismos propriamente de segurança, as velhas estruturas da lei e da disciplina (FOUCAULT, 2008d, p. 14).

Embora cientes da justaposição dessas três grandes formas de se exercer o poder, apresentaremos a seguir as principais características de cada uma delas de modo a diferenciálas e para que possam servir de referência para as análises posteriores deste texto.

\section{A soberania}

A soberania pode ser definida como um tipo de sociedade marcada pela detenção do monopólio de poder por parte do Estado, na figura do soberano, de modo a garantir o controle das fronteiras e a paz interna. O primeiro capítulo do livro Vigiar e Punir (FOUCAULT, 2009) começa com a descrição do suplício de Damiens, acusado de parricídio:

Damiens fora condenado, a 2 de março de 1757, a pedir perdão publicamente diante da porta principal da Igreja de Paris aonde devia ser levado e acompanhado numa carroça, nu, de camisola, carregando uma tocha de cera acesa de duas libras; em seguida, na dita carroça, na Praça de Greve, e sobre um patíbulo que aí será erguido, atenazado nos mamilos, braços, coxas e barrigas das pernas, sua mão direita segurando a faca com que cometeu o dito parricídio, queimada com fogo de enxofre, e às partes em que será atenazado se aplicarão chumbo derretido, óleo fervente, piche em fogo, cera e enxofre derretidos conjuntamente, e a seguir seu corpo será puxado e desmembrado por quatro cavalos e seus membros e corpo consumidos ao fogo, reduzidos a cinzas, e suas cinzas lançadas ao vento (Foucault, 2009, p. 9).

O suplício judiciário é um ritual político, pois faz parte das cerimônias pelas quais se manifesta o poder do soberano. A infração prejudica o direito do que faz valer a lei: o crime, além de sua vítima imediata, ataca pessoalmente o soberano, pois a lei vale como a sua vontade. A intervenção do soberano não é uma arbitragem entre dois adversários, nem uma ação para fazer respeitar o direito de cada um, mas uma réplica direta àquele que ofendeu a sua autoridade.

O que sustentava a prática dos suplícios não era a economia do exemplo, mas a política do medo: tornar sensível a todos, sobre o corpo do criminoso, a presença encolerizada do soberano. O suplício não restabelecia a justiça; reativava o poder. A execução pública é mais uma manifestação de força do que uma obra de justiça; ou antes, é a justiça como força física, material e temível do soberano que é exibida.

Segundo Foucault (1988, p. 127), na soberania, o direito que é formulado como de "vida e morte" é, de fato, o direito de causar a morte ou de deixar viver. É um tipo histórico de sociedade em que o poder se exerce essencialmente como instância de confisco, mecanismo de subtração, direito de se apropriar de uma parte das riquezas: extorsão de produtos, de bens, de serviços, de trabalho e de sangue imposta aos súditos. O poder era antes 
de tudo um direito de apreensão das coisas, do tempo, dos corpos e, finalmente, da vida; culminava com o privilégio de se apoderar da vida para suprimi-la.

Embora os suplícios não constituíssem as penas mais frequentes da soberania, Michel Foucault inicia o livro com a descrição dramática de um suplício para sublinhar o que melhor caracterizava o poder soberano: em caso de infração da lei, a aplicação de uma punição correspondente. A soberania funcionava, portanto, a partir de um quadro jurídico, um sistema de código legal com divisão binária entre o permitido e o proibido e uma relação linear entre um tipo de ação proibida e um tipo de punição a ser aplicada.

\section{A disciplina}

Na segunda metade do século XVIII, a transição de uma penalidade ostentatória e ritualística, como eram os suplícios, para uma punição generalizada pelo corpo social, como foi proposta pelos reformadores penais, culminou em uma tecnologia de poder que Foucault (2009, p. 129) denomina de disciplina.

A disciplina, assim como os suplícios, é uma tecnologia de poder que atua sobre o corpo, mas de uma maneira completamente diferente: de maneira discreta e de aplicação automática, ela atua sobre um corpo que se manipula, se modela, se treina, que torna-se obediente e hábil e cujas forças se multiplicam. Em outras palavras, um adestramento cuja noção principal é a de docilidade, um corpo que pode ser submetido, utilizado, transformado e aperfeiçoado. Foucault (2009, p. 134) reconhece que muitos processos disciplinares existiam há muito tempo nos conventos, nos exércitos ou nas oficinas. O que há de novo para ele é que as disciplinas se tornaram no decorrer dos séculos XVII e XVIII fórmulas gerais de dominação que se espalharam para diversas instituições sociais e mesmo para a sociedade em seu conjunto.

Embora Foucault já reconheça as estratégias das disciplinas espalhadas pela sociedade como um todo, trata-se de um tipo de poder que utiliza como técnica fundamental de funcionamento o confinamento. São nas instituições sociais fechadas - escolas, hospitais, fábricas, prisões - que as disciplinas encontram as condições ideais de modo a exercer suas funções da forma mais adequada.

O panóptico é a figura arquitetural paradigmática do poder disciplinar. Trata-se de um modelo de prisão imaginado por Jeremy Bentham e construído no final do século XVIII cujo objetivo era induzir no detento um estado consciente e permanente de visibilidade que assegura o funcionamento automático do poder. O princípio é o seguinte: na periferia uma construção em anel; no centro, uma torre: esta é vazada de largas janelas que se abrem sobre a face interna do anel; a construção periférica é dividida em celas, cada uma atravessando toda a espessura da construção; elas têm duas janelas, uma para o interior, correspondendo às janelas da torre; outra, que dá para o exterior, permite que a luz atravesse a cela de lado a lado. Basta então colocar um vigia na torre central, e em cada cela trancar um louco, um doente, um condenado, um operário ou um escolar. Estes interiorizam uma vigilância ininterrupta, mesmo quando não estão sendo vigiados, pois não podem ver a presença ou ausência dos guardas na torre central (FOUCAULT, 2009, p. 190).

O sucesso da disciplina como técnica de poder se deve ao fato de ela tomar os indivíduos ao mesmo tempo como objetos e como instrumentos de seu exercício. Talvez o ideal panóptico fosse atingido quando não mais houvesse necessidade de um guarda na torre central. O próprio detento seria portador do poder e princípio de sua própria sujeição. Vitória perpétua e por antecipação que prescinde de quaisquer amarras: grades, ferros, coleiras ou muros. As instituições disciplinares perfeitas estão destrancadas e livres para funcionar de 
maneira difusa, múltipla e generalizada pelo campo social inteiro, buscando a "transparência" máxima.

Essas disciplinas que a era clássica elabora em locais precisos e relativamente fechados [...] Bentham sonha fazer delas uma rede de dispositivos que estariam em toda parte e sempre alertas, percorrendo a sociedade sem lacuna nem interrupção (FOUCAULT, 2009, p. 197).

As técnicas de poder já não são localizáveis, mas difusas e espalhadas por todo o corpo social. Gilles Deleuze afirma que,

[...] a disciplina não pode ser identificada com uma instituição nem com um aparelho, exatamente porque ela é um tipo de poder, uma tecnologia, que atravessa todas as espécies de aparelhos e de instituições [...] Não há um lugar privilegiado como fonte de poder nem podemos acertar sua localização pontual; o poder é local porque nunca é global, mas ele não é local nem localizável porque é difuso (DELEUZE, 2005, p. 35 e 36).

Sobre a aplicação do modelo panóptico fora do contexto da prisão,

[...] cada vez que se tratar de uma multiplicidade de indivíduos a que se deve impor uma tarefa ou um comportamento, o esquema panóptico poderá ser utilizado [...] Ele é aplicável onde [...] nos limites de um espaço que não é muito extenso, é preciso manter sob vigilância um certo número de pessoas (FOUCAULT, 2009, p. 195).

Vê-se, portanto, que a inscrição do panóptico em uma instituição social fechada, como a prisão, é tão somente o início de um modelo difuso de vigilância social baseado na constituição de uma rede de olhares não mais hierárquica (para Foucault, não existe uma fonte de irradiação do poder, que não está apenas localizado na figura do Estado, por exemplo) em que "cada camarada torna-se um vigia" (BENTHAM, apud FOUCAULT, 2008b, p. 215). O panóptico deve ser entendido como uma metáfora, ou seja, o que Foucault (2009, p. 186) chama de panoptismo.

\section{A biopolítica}

No Ocidente, a transformação dos mecanismos de poder no sentido de produzir forças, fazê-las crescer e ordena-las mais do que barrá-las, dobrá-las ou destruí-las, um poder que exige a gestão da vida e que se ordena em função de seus reclamos, suas exigências de desenvolvimento, é o que Foucault (1988, 2008c; 2008d) denomina biopolítica ou biopoder.

Segundo Foucault (1988), pode-se dizer que o velho direito soberano de causar a morte ou deixar viver foi substituído por um poder de causar a vida ou deixar morrer. Progressiva desqualificação da morte, que fica escondida, muitas vezes oculta, tornando-se o ponto mais secreto da existência.

A biopolítica é um complemento das funções disciplinares que se exerciam positivamente sobre a vida dos indivíduos a partir dos treinamentos, exercícios e gestão de seus corpos. Porém, agora, os objetivos são traçados não mais em nome dos corpos individuais, mas em nome da existência biológica de uma população humana, ao nível da raça e espécie humanas, em nome de sua necessidade de viver. Daí a importância para a biopolítica das técnicas estatísticas para regulação de fenômenos como a natalidade, a mortalidade e a 
longevidade de uma população. Trata-se de constituir para uma população algo que seja um meio de vida, de existência, de trabalho.

O contexto de nascimento da biopolítica é aquele do desenvolvimento do capitalismo e das práticas liberais que o acompanham. Num contexto de concorrência entre os Estados europeus durante o século XVIII, o fortalecimento de cada um deles dependia do aumento de suas riquezas internas. Em prol de uma economia máxima, os Estados desenvolvem mecanismos de autolimitação em nome de sua própria sobrevivência. $\mathrm{O}$ objetivo passa a ser não governar demais, o que precisa ser respeitado, caso contrário, haverá imediatamente consequências negativas para o próprio Estado, ou seja, possibilidade de sucesso ou fracasso.

O princípio liberal é aquele do laisser-faire, ou seja, deixar as pessoas fazerem, as coisas passarem, os circuitos se desenvolverem, de acordo com as leis naturais do mercado, o que resulta em um aumento geral das liberdades, expressão cujo significado não é mais aquele vinculado aos privilégios de uma pessoa particular, mas à possibilidade de movimento, de deslocamento, processo de circulação tanto das pessoas quanto das coisas. Para Foucault (2008d, p. 63-64), tal liberdade é o correlato da implantação dos dispositivos de segurança e vice-versa: liberdade e segurança numa relação recíproca de equilíbrio.

$\mathrm{Na}$ medida em que o liberalismo se preocupa com a "liberdade" dos indivíduos, se instaura, no cerne da própria prática liberal, uma relação problemática entre aquilo que produz a liberdade e aquilo que deve limitá-la, controlá-la e coagi-la. Foucault (2008d, p. 63-64) se pergunta então qual vai ser o princípio de cálculo desse custo de fabricação da liberdade e conclui pela instauração de mecanismos de segurança, surgidos com a intenção de proteger o interesse coletivo contra os interesses individuais e vice-versa.

É neste sentido que o autor afirma que o liberalismo se insere num contexto em que terá, a cada instante, de arbitrar a liberdade e a segurança dos indivíduos em torno da noção de perigo, este entendido não no sentido das grandes ameaças, mas em relação ao aparecimento, a emergência, a invasão dos perigos cotidianos perpetuamente animados.As "liberdades" têm como correspondência certa "complexificação", aumento dos desvios e, portanto, uma maior exigência de controle. ${ }^{3}$

Assim como nas leis de mercado, a naturalidade aparece também na população, que cresce, decresce, se transforma e se desloca segundo leis próprias de transformação e deslocamento. Entre os indivíduos, uma série de interações cujos vínculos não são aqueles desejados pelo Estado, mas são espontâneos. A finalidade é governá-la no sentido de aumentar a sua sorte, suas riquezas, sua longevidade, sua saúde. A população entendida no sentido de força produtiva.

Para Foucault,

[...] garantir a segurança desses fenômenos naturais que são os processos econômicos ou os processos intrínsecos à população, é isso que vai ser o objetivo fundamental da governamentalidade [...] Agora só se pode governar bem se, efetivamente, a liberdade ou certo número de formas de liberdade forem respeitados (FOUCAULT, 2008d, p. 474-475).

\footnotetext{
${ }^{3} \mathrm{Na}$ intenção de ratificar a sobreposição das sociedades disciplinares e biopolíticas e destacar a importância de se entender o modelo panóptico fora das instituições sociais fechadas, cabe registrar aqui a menção que faz Foucault sobre o que significava o panoptismo, para Bentham, no contexto do liberalismo: “[...] o panóptico é a própria fórmula de um governo liberal, porque, no fundo, o que deve fazer um governo? Ele deve, é claro, dar espaço a tudo o que pode ser a mecânica natural tanto dos comportamentos como da produção. Deve dar espaço a esses mecanismos e não deve ter sobre eles nenhuma outra forma de intervenção, pelo menos em primeira instância, a não ser a da vigilância [...] o panoptismo não é uma mecânica regional e limitada a instituições [...] é uma fórmula política geral que caracteriza um tipo de governo" (Foucault, 2008d, p. 91-92).
} 
No cálculo do liberalismo, a (in)segurança entra na série de realidades inevitáveis, naturais, que ocorrem a partir da relação dos homens entre si, da sua coexistência em áreas densamente povoadas, como as cidades, nos locais de trabalho, nas áreas de circulação. A emergência de uma naturalidade da sociedade exige não exclusivamente intervenções ou regulamentações, mas também formas de gerir e administrar esses processos naturais ou, em todo caso, levá-los em conta, fazê-los agir ou agir de acordo com eles.

As "soluções" apresentadas se inserem em um contexto de gestão ou governo da (in)segurança, da criminalidade, dos desvios, etc., no sentido de que é mais útil e mais seguro governar os seus efeitos do que pensar e/ou enfrentar os problemas que os alimentam. ${ }^{4}$ Tratase de deixar que ocorram para melhor governá-los e/ou canalizá-los numa direção útil. ${ }^{5}$

Há, de acordo com Agambem (2014), uma perturbação da relação hierárquica tradicional entre as causas e os efeitos no que se refere a segurança. Segundo ele é vão ou custoso governar as causas e mais útil e seguro governar os efeitos. Autor utiliza o exemplo da biometria para concluir que é apenas com o crime cometido que o Estado pode intervir com eficácia quando dispõe de dados individuais para eventualmente punir um suspeito. Poderíamos estender o exemplo para as câmeras de vigilância como política de segurança pública que, inseridas numa política econômica de contenção de gastos, acabam por reduzir o efetivo policial nas ruas - o que talvez representasse uma prevenção - e estão em estado de espera para que o crime aconteça para depois ser eventualmente punido.

Foucault apresenta dois exemplos de "solução" de determinado problema segundo as três modalidades de poder. O primeiro refere-se à abordagem do poder sobre três doenças: a lepra, a peste e a varíola (FOUCAULT, 2008d, p. 13-14). A exclusão dos leprosos na Idade Média européia se fazia essencialmente em torno da oposição binária entre leprosos e não leprosos (mecanismo soberano). Os regulamentos relativos à peste nos séculos XVI e XVII tinham por funções precisas quadrilhar literalmente as regiões, as cidades no interior das quais existe a peste, colocar inspetores e guardas nas ruas e quarteirões, indicando as pessoas quando podem sair, como a que horas, o que devem fazer em casa, que tipo de alimentação devem ter, proibindo este ou aquele tipo de contato, obrigando-as a se apresentar e abrir a casas aos inspetores (mecanismo disciplinar). O problema se coloca de maneira inteiramente diferente a partir do século XVIII em relação à varíola: tratava-se de saber quantas pessoas pegaram a doença, com que idade, qual o índice de mortalidade, quais as sequelas, que riscos se correm quando da inoculação, ou seja, não se trata mais da exclusão ou da quarentena, e sim de quais são os efeitos estatísticos sobre a população em geral (mecanismo de segurança).

O segundo é relativo à criminalidade (FOUCAULT, 2008d, p.6-7). A soberania faz valer uma lei penal simples em caso de transgressão das regras: "não matarás, não roubarás" pode resultar na morte ou na multa. A disciplina complementa a lei penal da soberania, de um

\footnotetext{
${ }^{4}$ Há, de acordo com Agambem (2014), uma perturbação da relação hierárquica tradicional entre as causas e os efeitos no que se refere a segurança. Segundo ele é vão ou custoso governar as causas e mais útil e seguro governar os efeitos. Autor utiliza o exemplo da biometria para concluir que é apenas com o crime cometido que o Estado pode intervir com eficácia quando dispõe de dados individuais para eventualmente punir um suspeito. Poderíamos estender o exemplo para as câmeras de vigilância como política de segurança pública que, inseridas numa política econômica de contenção de gastos, acabam por reduzir o efetivo policial nas ruas - o que talvez representasse uma prevenção - e estão em estado de espera para que o crime aconteça para depois ser eventualmente punido.

${ }^{5}$ Ver Garland (2008) para a transição das políticas de controle do crime de uma sociedade de bem-estar social para uma sociedade neoliberal, a partir dos anos 1970 e 1980. Os exemplos são os Estados Unidos e o Reino Unido.
} 
lado, com toda uma série de vigilâncias, olhares, controles, esquadrinhamentos diversos que permitem descobrir o ladrão antes mesmo de ele vir a roubar; de outro com o encarceramento impondo ao culpado uma série de mecanismos para sua eventual transformação. Finalmente, a biopolítica, apoiada nas técnicas estatísticas, impõe a gestão da criminalidade ao se perguntar: qual é a taxa média da criminalidade de determinado tipo? Como se pode prever a ocorrência e as quantidades de determinados roubos, numa sociedade dada, numa cidade dada, num bairro dado? Quais sistemas penais fazem com que essas taxas aumentem ou diminuam? Quanto custa, quais são os prejuízos à sociedade, de determinado tipo de criminalidade? Quanto custa a repressão da criminalidade? O que é melhor, relaxar um pouco com o roubo ou relaxar um pouco a repressão? Se o culpado é encontrado, vale a pena puni-lo? Quanto custa puni-lo? Ele representa de fato um perigo à sociedade?

De maneira geral, a questão que se coloca será a de saber como, no fundo, manter um tipo de criminalidade, ou seja, o roubo, dentro de limites que sejam social e economicamente aceitáveis e em torno de uma média que vai ser considerada, digamos, ótima para um funcionamento social dado (FOUCAULT, 2008d, p. 8).

Inserir a criminalidade numa série de acontecimentos prováveis, num cálculo de custo e, finalmente, em vez de instaurar uma divisão binária entre o permitido e o proibido, estabelecer os limites do aceitável. Eis as características do dispositivo de segurança.

\section{O poder e suas espacialidades}

Essencial para nós é pensar nas técnicas de poder apresentadas acima em termos de espaço. Neste sentido, é fundamental a contribuição de Foucault (2008d, p. 16-17) sobre a organização espacial no contexto das três modalidades de poder, simultaneamente como resultado e condição para o seu exercício. Grosso modo, a soberania se exerce nos limites de um território, a disciplina sobre o corpo em uma repartição espacial definida e a segurança sobre o conjunto de uma população. Vejamos isto em detalhes a partir dos exemplos fornecidos por Foucault sobre a organização de algumas cidades européias, antes muradas, isoladas e diferenciadas em relação ao campo e que a partir do século XVIII precisaram se adaptar às exigências de circulação que o desenvolvimento comercial e o crescimento demográfico apresentavam.

O poder soberano deveria ser exercido sobre um território, este entendido aqui na sua acepção "tradicional", restrita, vinculado à soberania do Estado centralizado sobre um substrato físico (HAESBAERT, 2008, p. 156). ${ }^{6}$ Citando um texto do século XVII, La Métropolitée, de Alexandre Le Maître, Foucault (2008d, p. 18) descreve a eficácia política de um território soberano. Um território organizado deveria apresentar uma disposição espacial adequada: deveria apresentar a forma de um círculo em cujo centro estaria a capital, centro simbólico e material de irradiação do poder para o restante do território onde deveriam viver somente o soberano, seus oficiais e aqueles artesãos e comerciantes indispensáveis ao funcionamento da corte; em sua volta as pequenas cidades onde viviam os artesãos; e nos seus arredores, os campos onde viviam os camponeses.

\footnotetext{
${ }^{6}$ Embora o substrato físico seja aceitável a respeito da soberania jurídica sobre um território não povoado, Foucault (2008d, p. 16) reconhece que na prática cotidiana o poder soberano se exerce sobre uma multiplicidade humana.
} 
Três círculos concêntricos absolutamente bem demarcados. O problema da eficácia de tal organização espacial surge quando, dentro de um sistema de soberania estrita, é preciso assegurar o desenvolvimento econômico máximo por intermédio do comércio.

No caso das disciplinas, a correspondência espacial vincula-se uma construção ideal num espaço vazio. Foucault (2008d, p. 21) utiliza como exemplo a cidade francesa de Richelieu, construída "a partir do nada", utilizando-se como modelo de forma o acampamento militar romano. A cidade é pensada de início a partir de uma figura geométrica que é uma espécie de módulo arquitetônico, o quadrado ou o retângulo por sua vez subdividido, por cruzes, em outros quadrados e retângulos. Eis a descrição da cidade:

[...] há um eixo de simetria, mas que é enquadrado e que se torna funcional graças a dissimetrias bem calculadas. Numa cidade como Richelieu, por exemplo, vocês têm uma rua mediana, que divide efetivamente em dois retângulos o retângulo da cidade, e outras ruas, algumas delas paralelas a essa rua mediana, outras perpendiculares, mas que estão em distâncias diferentes, umas mais próximas, outras mais afastadas, de tal modo que a cidade é subdividida, sim, em retângulos, mas em retângulos que são, uns grandes, outros pequenos, com uma gradação do maior ao menor [...] do lado dos retângulos maiores, onde a trama é larga, onde as ruas são largas, é aí que as pessoas devem morar. Já onde a trama é mais estreita, é aí que devem estar o comércio, os artesãos, as lojas, é aí também que deve haver uma praça em que se realizarão as feiras [...] e do lado das moradias, do bairro residencial, em que os retângulos são mais largos, haverá duas categorias de casas, as que dão para a rua principal ou para as ruas paralelas à principal, que vão ser casas de um certo número de andares, dois creio, com mansarda e, nas ruas perpendiculares, as casas menores, de um só andar: diferença de status social, diferença de fortuna, etc (FOUCAULT, 2008d, p. 22-23).

Tal rigor na distribuição e divisão do espaço é característico das disciplinas e se insere num contexto das necessidades de vigilância e restrição das comunicações perigosas. Evitamse ao máximo os espaços livres e prontos para vários usos e lugares determinados são construídos para funções preestabelecidas.

Observa-se que a associação das disciplinas com os espaços fechados das instituições sociais panópticas clássicas - escolas, hospitais, prisões, fábricas - com seus muros, cercas e restrições, que criam um local heterogêneo aos demais, já não é suficiente. Uma cidade inteira pode exercer uma função disciplinar.

O espaço da segurança está diretamente vinculado ao problema da circulação. Foucault (2008d, p. 23) recorre ao exemplo da cidade de Nantes: tratava-se de um planejamento urbano que deveria desfazer as aglomerações desordenadas, abrir espaço para as novas funções econômicas e administrativas, regulamentar as relações com o entorno rural e prever o crescimento.

Não se tratava de construir ou reconstruir uma cidade, e sim torná-la organizada à circulação. Em primeiro lugar, abrir eixos que atravessassem a cidade e ruas largas o suficiente para assegurar quatro funções: a primeira, de higiene e arejamento para eliminar o perigo do contágio de doenças em bairros demasiados apertados; em segundo lugar, garantir o comércio interior; em terceiro lugar, garantir o comércio externo; em quarto lugar, possibilitar a vigilância no momento em que os muros precisavam ser derrubados para atender as necessidades do comércio e a cidade havia se tornado mais insegura. Assim, de acordo com Foucault (2008d, p. 24) maximizava-se a "boa" circulação (econômica) e minimizava-se a "má" (doenças, criminosos, etc.). 
Enquanto a disciplina constrói um espaço artificial cujo objetivo é a perfeição disciplinar, a segurança trabalha com um espaço já "dado". Ela precisa adequar os elementos artificiais - ruas, casas, praças, eventualmente abrir ruas - e naturais - ar, rios, árvores - já disponíveis de modo a maximizar os efeitos positivos e minimizar os inconvenientes, sabendo que nunca poderá suprimi-los. Sendo assim, a segurança opera segundo probabilidades: Qual a possibilidade de ser contagiado? Qual o local mais seguro? Onde é a maior incidência de crimes? Por onde circulam os vagabundos, os mendigos, os delinquentes?

Os elementos já dados assumem uma função e sua contrapartida: pela mesma rua em que se desenvolve o comércio também circulam assassinos; o ar indispensável à respiração é o mesmo que transmite doenças, etc. Isso é preciso levar em conta no planejamento, assim como o futuro: admitida a impossibilidade de solução dos problemas, busca-se governar os efeitos; leva-se em conta o que pode acontecer.

[...] acredito que possamos falar aqui de uma técnica que se vincula essencialmente ao problema da segurança, isto é, no fundo, ao problema da série. Série indefinida dos elementos que se deslocam: a circulação, número $\mathrm{x}$ de carroças, número $\mathrm{x}$ de passantes, número $\mathrm{x}$ de ladrões, número $\mathrm{x}$ de miasmas [...] É a gestão dessas séries abertas, que, por conseguinte, só podem ser controladas por uma estimativa de probabilidades, é isso, a meu ver, que caracteriza essencialmente o mecanismo de segurança [...] O espaço próprio da segurança remete, portanto, a uma série de acontecimentos possíveis, remete ao temporal e ao aleatório, um temporal e um aleatório que vai ser necessário inscrever num espaço dado (FOUCAULT, 2008d, p. 2627).

O espaço da circulação é o que Foucault (2008d, p. 27) denomina de meio, o suporte e o elemento de circulação de uma ação. É um conjunto de dados naturais - rios, florestas, relevo, ar - e artificiais - ruas, avenidas, casas, edifícios -, uma materialidade que é o suporte de uma multiplicidade de indivíduos, a população. Atuar no sentido de garantir a segurança, garantir a circulação envolve a consideração destes dados naturais e artificiais.

Aparece aqui a questão da "naturalidade" da espécie humana e sua relação biológica com um meio artificial. A crescente artificialidade do meio modifica os rios, o clima, as florestas, tornando recantos outrora sadios em áreas degradadas. A aglomeração urbana, os problemas sanitários, a circulação de doenças vinculadas à artificialidade de uma meio orientam o planejamento no sentido de se preocupar com essas questões. Garantir a segurança da população significa intervenções políticas e econômicas no ponto de articulação em que os elementos físicos vêm interferir na natureza da espécie humana.

A interpretação de Haesbaert (2008, p. 157) do "meio" como espaço da segurança apresentado por Foucault envolve uma reconfiguração da expressão territorial, agora moldada muito mais por um de seus elementos indissociáveis que são as redes. Como está diretamente associada ao meio, a população - e seus fluxos - passa a ser o objeto por excelência do controle da circulação.

A correspondência entre as três modalidades de poder e seus respectivos espaços pode ser assim resumida:

[...] enquanto a soberania capitaliza um território, colocando o problema maior da sede do governo, enquanto a disciplina arquiteta um espaço e coloca como problema essencial uma distribuição hierárquica e funcional dos elementos, a segurança vai procurar criar um ambiente em função de acontecimentos ou de elementos possíveis, séries que vai ser preciso 
regularizar num contexto multivalente e transformável (FOUCAULT, 2008d, p. 27).

\section{O poder e suas respectivas espacialidades na gestão dos riscos nas cidades brasileiras contemporâneas: um exercício de análise}

Pensar de que maneira as cidades contemporâneas se organizam em torno dos riscos exige que consideremos as três modalidades de poder esboçadas e suas respectivas espacialidades. Seja através das formas sutis ou repressivas de controle social por parte do Estado, seja através da atuação da iniciativa privada no mercado da segurança, o fato é que aspectos de soberania, disciplina e controle estão presentes nos espaços urbanos e são parte de um projeto de gestão da insegurança. Para efeito de análise, nos concentraremos em quatro maneiras de gestão dos riscos que, acreditamos, são manifestações atuais de exercícios de poder que apresentamos anteriormente: a atuação da polícia militar, o encarceramento em massa, os condomínios fechados e as câmeras de vigilância em espaços públicos.

\section{A soberania atualizada: atuação da polícia militar e encarceramento em massa}

Embora seja comum, nos dias atuais, nos referirmos às formas mais sutis de controle social e a discrição do exercício do poder que ela acarreta, persiste, em escala mundial, o controle repressivo do território em suas mais diferentes escalas através da "mão de ferro" do Estado, tanto através da atuação das polícias quanto de uma política de encarceramento massivo. No Brasil, o drama é ainda maior considerando a cultura autoritária que é parte da sociedade brasileira e de suas instituições, como é o caso da polícia militar, a que mais mata no mundo, principalmente os jovens negros das periferias das grandes cidades.

As execuções sumárias de indivíduos ou grupos de indivíduos pobres, em seus espaços estigmatizados, por parte da polícia ou de organizações paramilitares, como as milícias, indicam a atuação do Estado no sentido de conter certa criminalidade, o que nos remete, de certa forma, às práticas dos suplícios. Com todas as ressalvas, distorções e anacronismos que tal comparação suscita, o que está em jogo, de fato, é o velho direito do Estado de causar a morte ou deixar viver, quando o poder é uma instância de confisco, neste caso a vida dos indivíduos pobres. Assim como eram os suplícios, trata-se, neste caso, da presença encolerizada do Estado, através de seu braço armado, a polícia, sobre os corpos dos criminosos, de modo a reativar o poder a partir da disseminação da política do medo.

Trata-se de uma situação preocupante de desvalorização das vidas das pessoas pobres que precisam muitas vezes ser combatidas e em alguns casos até mesmo extirpadas. Em certa medida, a gestão dessas vidas entra num cálculo econômico cuja conclusão se dá em duas frentes: em primeiro lugar, essas vidas não produzem riqueza no sentido em que não há para elas emprego, o que limita ou até mesmo impede que participem do circuito de consumo ${ }^{7}$; em

\footnotetext{
${ }^{7}$ Estamos nos referindo a um quadro estrutural de desigualdades e injustiças da sociedade brasileira que foi agravado com os fenômenos de desindustrialização, acumulação flexível, terceirização, ajustes estruturais, etc., que ocorreram na esteira das políticas econômicas neoliberais, e que destinam trabalhadores pobres do setor formal para os setores informais da economia. De acordo com Souza (2008), o que já era precário - baixas remunerações, conforto, segurança do trabalho - se torna precaríssimo em razão do desamparo trabalhista e previdenciário, da maior instabilidade e da deterioração do padrão de consumo. O autor se refere a essa massa de trabalhadores como hiperprecariado, "o heterogêneo universo dos trabalhadores informais e todos aqueles que sobrevivem em circunstâncias de grande vulnerabilidade e mesmo perigo, morando em espaços extremamente desconfortáveis e muitas vezes insalubres ou improvisados e exercendo ocupações estigmatizadas." (SOUZA,
} 
segundo lugar, muitas dessas vidas, devido a sua baixa qualificação e/ou absoluta incapacidade para se inserir no mercado de trabalho formal, não servem nem mesmo para compor um "exército industrial de reserva" que serviria ao menos para manter pressão sobre os trabalhadores, mantendo baixos seus salários.

Uma interpretação possível dessa gestão liberal das vidas dos pobres é a marca autoritária do Estado brasileiro ao lidar com assuntos relativos à segurança. Segundo Zanotelli et. al. (2011, p. 55), ao contrário do caso dos países europeus, onde as forças armadas atuavam no sentido de controlar as fronteiras, enquanto a polícia cuidava da "paz interna", no caso brasileiro elas se mostravam desde o início da constituição do Estado nacional como responsáveis da ordem interna - utilização do exército para combater as rebeliões e os movimentos sociais, golpes de Estado, ditaduras -, como demonstra a própria denominação de Polícia Militar e sua atuação como braço armado do Estado para controle social durante a ditadura militar brasileira. Os próprios cidadãos eram muitas vezes considerados inimigos, como os casos de contestação ao regime militar, enquanto no caso europeu tal situação de "inimigo interno" se manifestava tão somente em contextos específicos - caso das variações dos estados fascistas na Alemanha, Itália, Espanha e Portugal. A cultura do Outro visto como inimigo vincula-se agora não mais ao guerrilheiro ou ao comunista, personagens tão caros à ditadura militar brasileira, mas ao bandido, ao marginal ou ao morador de rua.

Se a banalização das mortes, como discutido acima, nos remete à atualidade dos suplícios, por outro lado, outra forma de controle social, a política de encarceramento massivo, levada a cabo em diversos países, inclusive no Brasil, da qual os Estados Unidos talvez sejam o melhor exemplo, nos remete ainda à forte presença do estado soberano no controle do território.

A tese defendida por Wacquant (2001) é a de que o avanço do neoliberalismo, inicialmente sobre os Estados Unidos e a Inglaterra sob os comandos de Reagan e Thatcher, e posteriormente sobre os demais países, e as consequências do desmantelamento das estruturas sociais herdadas de um Estado de bem-estar social - desemprego em massa, generalização do trabalho assalariado precário e encolhimento da proteção social - tem como corolário uma política de Estado destinada a conter os riscos e inconvenientes através de um encarceramento massivo da população pobre. É o que o autor considera a transição de um Estado social para um Estado penal.

Para o autor, a penalidade neoliberal é ainda mais prejudicial para os países de acentuadas desigualdades socioeconômicas e de poucas tradições democráticas cujas instituições são incapazes de amortecer os choques causados pela mutação do trabalho e do indivíduo em anos mais recentes, como é o caso do Brasil. A forte concentração de riqueza associada à pobreza de massa alimentam o crescimento da violência, transformada em um dos principais flagelos da sociedade urbana brasileira, sobretudo quando consideramos o problema da criminalidade ligado ao tráfico de armas e drogas ilícitas, responsáveis diretas pela generalização do medo e da insegurança. Por outro lado, a insegurança é agravada pela atuação do Estado, por meio das polícias, cuja tradição autoritária e repressiva, de origem histórica e que se fortaleceu no período da ditadura militar, se manifesta pelo uso rotineiro da violência contra as classes populares, por meios como as torturas, os linchamentos e os assassinatos.

2008, p. 131-132). Neste contexto, destacam-se as atividades informais ligadas ao tráfico de drogas de varejo. Tal situação merece ser relativizada considerando certa distribuição de riqueza dos governos dos presidentes Lula e Dilma e a consequente melhoria de vida material dos mais pobres, o que, infelizmente, está ficando para trás. 
EM

Em tais condições, desenvolver o Estado penal para responder às desordens suscitadas pela desregulamentação da economia, pela dessocialização do trabalho assalariado e pela pauperização relativa e absoluta de amplos contingentes do proletariado urbano, aumentando os meios, a amplitude e a intensidade da intervenção do aparelho policial e judiciário, equivale a (r)estabelecer uma verdadeira ditadura sobre os pobres (WACQUANT, 2001, p. 12).

Trata-se do que Souza (2008, p. 155) chama de "tentação penal", a busca de apoio nas instituições carcerárias para minimizar os efeitos da insegurança social ao tirar de circulação parte da massa desempregada, que não serviria, graças à sua baixa qualificação educacional, nem para compor um "exército industrial de reserva".

Certa ou errada para o caso dos Estados Unidos, de acordo com Soares (2013, p. 18) a interpretação de Wacquant para o encarceramento massivo não se aplica ao caso brasileiro, que coincide com os governos do PT (Partido dos Trabalhadores) quando houve redução das desigualdades e ampliação do emprego e da renda. O neoliberalismo por aqui significou, assim como em outros países, todos os benefícios ao mercado, poder econômico às elites e classes médias, mas também alguns benefícios sociais às classes populares que, em geral, tiveram suas vidas melhoradas.

De qualquer modo, nunca se prendeu tanto no Brasil. O encarceramento massivo que torna o país a quarta maior população carcerária do mundo, estaria relacionado à prioridade dada aos crimes contra o patrimônio e tráfico de drogas e não aos crimes contra a vida e os crimes de armas. Entre os presos, apenas 12\% cumprem pena por crimes letais, $40 \%$ são provisórios, e dois terços da população carcerária cumprem pena por crimes ligados ao patrimônio e às drogas. Ou seja, o Estado brasileiro prende muito e mal (SOARES, 2013, p. $18)$.

Isto estaria ligado à natureza militar da polícia brasileira - fortemente centralizada e hierarquizada - que resulta de uma cultura corporativa herdada da história de autoritarismo da sociedade brasileira, fortalecida durante o regime militar. O trabalho do policial "na ponta" não é independente, livre, valorizado, flexível, o que o permitiria avaliar, diagnosticar e tomar decisões adequadas aos problemas que se apresentam; ao contrário, a estrutura militar rígida e hierarquizada faz dos policiais militares simples subalternos nas ruas, que devem obedecer a ordens superiores ao longo dos turnos e trajetos do trabalho de vigilância.

O que restará ao trabalho policial cotidiano?

Varrer a rua com os olhos e a audição, classificando personagens e biótipos, gestos e linguagens corporais, figurinos e vocabulários, orientado pelo imperativo de funcionar, produzir, o que significa, para a PM, prender. Ad hoc, no varejo do cotidiano, só resta ao soldado procurar o flagrante, flagrar a ocorrência, capturar o suspeito. Os grupos sociais mais vulneráveis serão também, no quadro maior das desigualdades brasileiras e do racismo estrutural, os mais vulneráveis à escolha dos policiais, porque eles projetarão preconceitos no exercício de sua vigilância. Nos territórios vulneráveis, a tendência será atuar como tropa de ocupação e enfrentar inimigos (SOARES, 2013, p. 19).

Aos estereótipos que orientam a atuação das polícias no sentido de busca dos personagens sociais mais vulneráveis, soma-se à pressão exercida pelo governo, pela mídia e pela sociedade em geral pela busca de resultados em qualquer tipo de atividade, mas que para a polícia significa apenas uma coisa: prender sempre mais. A máquina precisa funcionar e ser produtiva, cuja medida depende do aumento da população carcerária e das prisões, sobretudo 
através de uma vigilância orientada pela busca do flagrante em personagens cuja fala, figurino, o rótulo já está pré-determinado, sobretudo pelo exemplo dos pequenos traficantes e usuários de drogas, sobre quem aumentou o rigor com a Lei de Drogas de 2006.

Embora o caso brasileiro talvez não forneça um exemplo adequado para a interpretação de Wacquant, é possível pensar que as melhorias das condições de vida das classes mais populares (o que ficando para trás) foi apenas uma etapa inicial na superação ou amenização das desigualdades que historicamente marcam a sociedade brasileira, mas que estão muito longe de tirar da pobreza e da miséria parcela significativa de uma população que encontra outros meios e alternativas de sobrevivência, muitas vezes ilícitos, como é o caso do tráfico de drogas, que gera todos os problemas de criminalidade e violência que conhecemos. Neste sentido, o modelo internacional de "manutenção da ordem", neste caso o encarceramento massivo, frente ao avanço dos problemas sociais gerados pelas políticas neoliberais tem rebatimentos no Brasil, no sentido de minimizar os riscos e inconvenientes através da prisão de uma boa parte da população pobre.

Mas se a política de encarceramento em massa verificada no Brasil atualiza a presença do poder soberano do Estado, por outro lado as prisões são a instituição paradigmática do poder disciplinar. Porém, no caso brasileiro, deve-se, como nos indica Zanotelli et. al. (2011, p. 55), relativizar a transposição do modelo europeu de penalidade, sobretudo o francês, apresentado por Foucault, marcado, até certo ponto, por certa "humanidade", e que não encontra paralelo com a realidade brasileira. ${ }^{8}$ As nossas prisões misturam as técnicas de disciplina apresentadas por Foucault (2009), com as práticas ritualísticas dos suplícios quando observamos os crimes com requintes de crueldade praticados no interior das prisões tanto pelos agentes públicos quanto pelos próprios presos.

A instituição-símbolo do poder disciplinar, a prisão, no que diz respeito à sociedade da segurança, manifesta seu momento de crise justamente no momento de sua proliferação, conforme Haesbaert (2010). O discurso do Estado a legitima em nome da segurança, mas os efeitos do aprisionamento dentro de uma sociedade em que as tecnologias informacionais (os celulares, por exemplo) faz com que um presidiário possa estar estrategicamente bem localizado dentro da prisão, o que nos interroga sobre a resignificação dos muros, cercas e guardas das prisões. Haesbaert (2010) propõe a utilização do termo "reclusão simulada", pois seria impossível, nesse contexto de tecnologias informacionais, manter confinado determinado grupo social, embora devemos considerar os efeitos concretos e devastadores das detenções do "excluídos" da sociedade que ali estão.

Mas, como dissemos, já não existe uma soberania do Estado no que se refere à gestão dos riscos. O governo dos riscos é uma importante frente de atuação da iniciativa privada, como pode ser verificado na expansão das empresas de segurança privada, de seguros, de aparelhos eletrônicos de segurança e em formas de moradia, como são os condomínios fechados, sobre os quais faremos a nossa abordagem.

\footnotetext{
${ }^{8}$ Por outro lado, parcelas das prisões dos países capitalistas mais "avançados" alcançam cada vez mais um aspecto de "humanidade". Davis (apud Soja, 2008, p. 434) descreve o Centro de Dentenção de Los Angeles como um hotel futurista ou edifício de escritórios, com efeitos artísticos, aspecto de luxo que é mais do que uma mera fachada. O interior da prisão foi desenhado para implementar um sofisticado programa de controle e manipulação psicológica: janelas sem barras, cores pastéis, carcereiros com elegantes jaquetas, jardins bem cuidados, área de recepção semelhante a um hotel, áreas com aparelhos de ginástica, etc.Nunca é demais enfatizar que esta descrição é relativa a algumas situações dos países capitalistas mais "avançados". Embora eventualmente possamos verificar construções de presídios mais "modernos", como são os casos dos centros de detenção provisória do Espírito Santo, destinados a manter presas pessoas que ainda aguardam julgamento, em geral a situação carcerária brasileira permanece dramática no que se refere ao tratamento destinado aos presos, ao número de presos por unidades prisionais, às condições físicas dos presídios, etc.
} 


\section{A disciplina e a biopolítica: os casos da proliferação de condomínios fechados e do uso de câmeras de vigilância em espaços públicos}

Os condomínios fechados são a versão residencial de uma categoria mais ampla de novos empreendimentos urbanos que Caldeira (2000, p. 258) chama de enclaves fortificados. Embora os condomínios existam há muito tempo no Brasil, as formas de moradia em forma de enclaves compartilham valores bem diversos dos antigos condomínios, principalmente porque são construções que se apresentam explicitamente a parte em relação à cidades, seja em relação à distância dos centros urbanos (os enclaves residenciais geralmente se localizam nas antigas periferias urbanas), seja em relação aos símbolos de separação (os enormes muros, guardas, câmeras, portarias). A justificação dos enclaves em geral e dos condomínios em particular é a demanda por um fator caro às grandes cidades brasileiras: a segurança. ${ }^{9}$ Por isso os enclaves residenciais são destinados às elites e classes médias, ou seja, aqueles setores sociais para os quais a segurança é, muitas vezes, uma obsessão.

No caso dos condomínios fechados, aspectos de disciplina e segurança, considerando a abordagem de Foucault, aparecem associados. Os condomínios fechados, por exemplo, são construídos e vendidos como espaços ideais de moradia, uma construção artificial cujo objetivo é atingir uma função disciplinar ideal: com seus muros, cercas, alarmes e câmeras, garantem a segurança a partir de uma vigilância irrestrita - inclusive entre os próprios moradores - ao mesmo tempo em que rejeitam a cidade ao oferecerem um simulacro de cidade em seu interior, um ideal de comunidade, com opções de lazer, academias, simulação de espaços públicos e em alguns casos opções de trabalho e escolas.

Os condomínios esforçam-se em se associar à natureza, representada - e simulada por bosques, áreas verdes, lagoas, mar, etc. A qualidade de vida, expressão tão presente nas propagandas, estaria vinculada a um retorno a um ambiente em que a cidade já não pode oferecer, onde os elementos físicos da natureza precisam, de alguma forma, estar presentes. Embora pensando no espaço de uma cidade, não seria este um dos atributos que Foucault conferia ao meio, um planejamento pautado em recriar um ambiente que a própria interferência humana modificou? As ilhas de tranquilidade em meio à natureza não estariam relacionadas, de um lado, a uma progressiva desqualificação da morte representada pelos "problemas" urbanos - trânsito, barulho, poluição, insegurança - e, por outro, pela exaltação da vida para fazer funcionar a espécie humana em sua natureza biológica?

Assim, para além dos aspectos óbvios de controle que são as cercas, os guardas, os muros, as câmeras, os condomínios fascinam como mercadoria de moradia, pois simulam um contraponto às supostas mazelas das cidades contemporâneas, ao se promoverem como espaços de qualidade de vida associados à vida em comunidade, à natureza, sempre evocando palavras de ordem como liberdade, felicidade, tranquilidade, etc. Desta forma produzem refúgios de um passado mitificado, ilhas de segurança a partir de signos que se apresentam como raridades no urbano. ${ }^{10}$

\footnotetext{
${ }^{9}$ É evidente que trata-se da criação de um ambiente em que criminalidade violenta e o discurso sobre ela estão associados na construção de uma narrativa em torno da insegurança urbana que favorece os interesses privados, neste caso, o setor da construção civil. Mas o fato é que tal narrativa “colou". Sobre o discurso da violência na mídia, ver Zanotelli e Medina (2008).

${ }^{10}$ Lefebvre (2008) refere-se às raridades do urbano como uma proliferação de signos da natureza em um ambiente urbano cada vez mais artificial, o que constituiria um simulacro da natureza para uma população urbana nostálgica de viver "como antigamente", a natureza enviando a um passado mitificado supostamente melhor. A fuga do urbano e um retorno à natureza são verificados nos parques e praças arborizados, a uma alimentação “saudável”, produtos ecologicamente corretos, turismo ecológico, jardins zoológicos, etc.
} 
Logo, não se trata de uma segurança que se exerce apenas por enclausuramento, mas de um sentimento de segurança que está associado à busca de pureza, que se manifesta pelo retorno à natureza, à comunidade, ao silêncio, à tranquilidade e à convivência entre iguais (no pensamento, nos costumes, nas opiniões, nas escolhas). O habitat na forma de condomínios é um convite à vida, uma maneira de direcionar a população que por eles possa pagar aos cuidados com a saúde e por isso não cessa de oferecer serviços de lazer (piscinas, quadras, academias), natureza (bosques, lagoas, praias) e convívio social (churrasqueiras e ideal de "comunidade").

As prisões e a casa dos loucos representavam, no poder disciplinar, a maneira pela qual um saber-poder encontrou para manter fora de circulação os que não se enquadravam à ordem vigente. Mantê-los afastados era uma condição para que fossem transformados para serem reinseridos na sociedade. É interessante pensar o habitat na forma de condomínios no sentido inverso. $\mathrm{Na}$ impossibilidade de afastar todos os problemas da sociedade (que agora são maiores e mais complexos) mantêm-se as pessoas em circulação, sob outras formas de controle, enquanto alguns privilegiados resolveram se afastar. Foge-se das mazelas ao invés de excluí-las.

É preciso sublinhar que os condomínios exclusivos representam tão somente um exemplo dos espaços fechados que se multiplicam pelas cidades. Há outros enclaves fortificados: poderíamos mencionar, por exemplo, a disseminação de espaços fechados para consumo, como são os shoppings centers e os centros empresariais e de serviços que se apresentam cada vez mais como espaços exclusivos e controlados.

Caminhamos neste sentido à reestruturação das cidades em torno de espaços fechados normatizados e controlado sobre os quais Soja (2008, p. 419), retomando uma expressão de Foucault, refere-se como "arquipélago carcerário", um conjunto de ilhas de confinamento destinadas a manter sob controle as multiplicidades de indivíduos que compõem as cidades. Faz sentido aqui a advertência de Foucault sobre os atributos das disciplinas no espaço quando lugares determinados são construídos para funções preestabelecidas, cujo rigor na distribuição e divisão se insere num contexto das necessidades de vigilância.

Evidentemente que aspectos de disciplina e segurança são verificados em formas mais sutis que prescindem dos clássicos símbolos de controle, como os muros, as cercas e os guardas, que já não são mais indispensáveis. $\mathrm{O}$ desenvolvimento tecnológico proporcionou a oportunidade de enquadramento total e permanente em espaços abertos destinados a manter sob controle os fluxos de pessoas, automóveis, informações, mercadorias, etc., como nos ensina a proliferação de controles biométricos, a espionagem na internet e as câmeras destinadas à vigilância dos espaços públicos, às quais nos ateremos mais especificamente. Mas antes, uma abordagem das tecnologias de controle à luz do conceito de meio técnicocientífico-informacional (SANTOS, 2008).

\section{O meio técnico-científico-informacional e a sociedade de controle}

A (re)estruturação das cidades contemporâneas em nome de uma certa (in)segurança encontra nas tecnologias de informação, registro e armazenamento de dados uma de suas frentes fundamentais de atuação. Assim como advertiu Foucault (2008d, p. 11) de que os mecanismos de poder devem ser entendidos como um aperfeiçoamento das técnicas, uma abordagem possível das tecnologias atuais de segurança é a partir do conceito de meio técnico-científico-informacional.

Tendo como referência o conceito de técnica, Santos (2008, p. 234) propõe uma periodização dos diferentes meios geográficos em três fases (e seus respectivos períodos): o meio natural, o meio técnico e o meio técnico-científico-informacional. 
O meio natural era utilizado sem grandes modificações, sendo as técnicas e o trabalho humanos associados com as leis naturais e dependentes delas. A sociedade local era, simultaneamente, criadora das técnicas utilizadas, comandantes dos tempos sociais e dos limites de sua utilização.

Com o surgimento das máquinas, o meio natural começa a dar lugar ao meio técnico, transição que não acontece de maneira simultânea em todos os lugares. Neste período, os instrumentos representam prolongamentos do território, verdadeiras próteses que auxiliam cada vez mais na subordinação das "leis naturais" ao domínio humano.

$\mathrm{O}$ momento posterior à Segunda Guerra Mundial assiste à emergência do meio técnico-científico-informacional, que se consolida em escala mundial a partir da década de 1970. Tal período se caracteriza pela inseparabilidade entre técnica e ciência, união que se estabelece sob a égide do mercado, ao mesmo tempo em que os objetos tendem a ser informacionais já que graças à extrema intencionalidade de sua produção e de sua localização eles já surgem como informação e o seu funcionamento é para gerar informação. A intencionalidade do objeto técnico atual marcará a artificialidade do fenômeno técnico contemporâneo, portador de virtualidades precisas que o distinguem e o distanciam das incertezas da natureza, mediante especializações cada vez mais estritamente funcionais.

O período técnico-científico-informacional marca a cientifização e a tecnicização da paisagem.

Por outro lado, a informação não apenas está presente nas coisas, nos objetos técnicos [...] como ela é necessária à ação realizada sobre essas coisas. A informação é o vetor fundamental do processo social e os territórios são [...] equipados para facilitar a sua circulação (SANTOS, 2008, p. 239).

O meio geográfico atual se difere dos anteriores também por seu aspecto global e os aparatos técnicos são indiferentes em relação ao meio em que se instalam. A tecnologia atual também se impõe como inevitável em função da força do imaginário correspondente, que facilita sua inserção em toda parte. Essa conjunção permite encarar o mundo como uma unidade. A manifestação pontual assegura o funcionamento dos processos encadeados a que podemos chamar de globalização, marcada pelo movimento, crescendo o número e a importância dos fluxos populacionais, informacionais e financeiros.

No período atual, o controle centralizado e a organização hierárquica conduzem à instalação de estruturas em que a informação essencial é exclusiva e apenas transita em circuitos restritos. A revolução informática e do controle tornou possível a realização da mobilidade generalizada, porém medida, controlada, prevista, que assegura aos centros de decisão um real poder sobre os outros pontos do espaço. Graças à construção técnica e social do tempo real é que vivemos uma instantaneidade percebida, uma simultaneidade dos instantes, uma convergência dos momentos.

Assim como representam possibilidades de comunicação as mais diversas, as tecnologias de informação são ferramentas que possibilitam o acompanhamento permanente dos indivíduos e são, por isso, ferramentas de poder. Segundo Deleuze (2007, p. 220), estamos entrando na era das sociedades de controle, quando novos tipos de sanções utilizam como suporte um aparato de redes de controle eletrônico e de segurança que estão distribuídas por toda a sociedade. Aparelhos de GPSs (Global Position Systems), aparelhos biométricos, satélites, redes de informática, câmeras de vigilância, etc., garantem um acompanhamento e enquadramento contínuo dos fluxos e permitem a produção indiscriminada de arquivos que poderão ser utilizados a qualquer momento como provas de elucidação de crimes e punição generalizada. 
Esta é uma análise convergente com um dos atributos que Foucault (2009, p. 181) confere às disciplinas, que produzem a individualidade a partir de um acúmulo de documentos que permitem a comparação e a classificação dos indivíduos e estão sempre disponíveis para uma utilização eventual. Nada mais atual para um período de registros permanentes através das redes sociais informáticas, exames médicos, arquivos de vídeos através de câmeras diversas, identificações biométricas etc., que se proliferam.

Porém, as sociedades de controle deixam para trás a técnica de confinamento, tão típica das disciplinas, e se caracterizam pela manifestação do poder em áreas abertas de circulação e gestão de fluxos. A tão propalada "informatização do cotidiano", característica fundamental das sociedades de controle, permite sanções que prescindem ou não estão exclusivamente relacionadas a todos os tipos de amarras físicas - muros, cercas, fechaduras, guardas, etc. Daí uma possível convergência também com a biopolítica ou os dispositivos de segurança, dos quais falava Foucault.

As sociedades do controle exigem um aparato tecnológico disponível, que dão forma ao período técnico-científico-informacional proposto por Santos (2008, p. 238). A inseparabilidade entre técnica e ciência é acompanhada pela extrema intencionalidade do objeto técnico, daí o seu caráter informacional. A intencionalidade das câmeras de vigilância, por exemplo, é verificável quando da sua produção (para gerar imagens 24 horas por dia) e de sua localização (em locais inseridos nos critérios de localização, como a violência, por exemplo) geram informação que procuram antecipar atos criminosos. Por outro lado, as imagens produzem "verdades" que seriam inquestionáveis, pois estão "ali", as câmeras portando virtualidades precisas que as distinguem e as distanciam das incertezas que pairam sobre os ambientes por elas vigiados. O seu papel é justamente produzir menos incertezas, mediante o disciplinamento das ações, tornando tudo pretensamente visível, transparente.

É importante registrar que as câmeras "oficiais" dos agentes de governo representam uma parte mínima das imagens da cidade produzidas atualmente. As câmeras estão espalhadas, dentro de escolas, nas ruas, praças, nos transportes coletivos, em supermercados e escritórios. Destaca-se ainda a multiplicação de aparelhos telefônicos móveis dotados de câmeras, garantindo a possibilidade das pessoas comuns produzirem imagens em qualquer lugar, a qualquer hora.

A maior complexidade das cidades contemporâneas a partir da proliferação de fluxos informacionais, financeiros e populacionais exige que as estratégias atuais de segurança estejam cada vez mais inseridas na lógica da informação. As polícias precisam estar equipadas de tecnologias diversas, tais como aparelhos biométricos, Sistema de Posicionamento Global (GPS), o Sistema de Informações Geográficas (SIG) para conhecer a espacialização dos crimes, para que possam atuar frente à criminalidade. Destacam-se, neste sentido, as câmeras de vigilância, uma vez que permitem uma visualização constante de porções estratégicas do território, equipados de modo a facilitar a circulação da informação.

O aspecto global do meio geográfico atual permite a migração das tecnologias de segurança em todos os lugares, pois os objetos técnicos são indiferentes e inevitáveis ao meio em que se instalam, uma vez que carregam consigo a força do imaginário correspondente. $\mathrm{O}$ mundo visto como unidade, porém, traz o efeito colateral de produção de novas violências, como a disseminação de medos globais pelos veículos de comunicação que constituem forças que alimentam a sensação de insegurança, construção técnica e social do tempo real que Santos (2008, p. 196) denomina de simultaneidade dos instantes ou convergência dos momentos. A sensação de insegurança é também causada pela disseminação de fluxos informacionais e populacionais no atual período de globalização.

A informação produzida pelas tecnologias de segurança corresponde ainda ao que Santos (2008) afirma a respeito do controle centralizado e a organização hierárquica que conduzem à instalação de estruturas em que a informação essencial é exclusiva e apenas 
transita em circuitos restritos. De fato, os dados relativos a questões envolvendo a segurança são de difícil acesso e muitas vezes sigilosos, o que pode resultar em uma interpretação, que é também muitas vezes o discurso oficial, de "preservação do sigilo" das práticas do Estado, mas que também pode indicar um certo receio de que todo o discurso da segurança possa ser questionado. Os centros de decisão detêm o monopólio da informação que legitima e autoriza o exercício de seu poder sobre todos os pontos do espaço.

As câmeras de vigilância, assim como os condomínios, parecem sobrepor as sociedades disciplinares e de segurança. A primeira observação importante é que a utilização de câmeras em espaços públicos pode ser entendida como uma atualização direta do panóptico: por que não pensar na presença física das câmeras e a sala de controle onde elas são operadas como a torre central e os cidadãos como os prisioneiros?

Porém, ao mesmo tempo, é preciso muito cuidado ao se fazer uma transposição direta do modelo teórico do panóptico para o caso da utilização de câmeras em espaços públicos. Como reconhece Foucault (2009, p. 191) o efeito mais importante do panóptico era induzir no detento um estado consciente e permanente de visibilidade que assegura o funcionamento automático do poder. A tarefa era facilitada porque o panóptico era um modelo de vigilância pensado para instituições sociais fechadas, como as prisões, onde os detentos possuíam ciência em relação à vigilância, ao mesmo tempo em que suas identidades eram conhecidas, o que facilitava futuras intervenções para propósito de controle.

O uso de câmeras de vigilância em espaços públicos, ao contrário, pressupõe o controle sobre espaços abertos de circulação. Seria incorreto dizer, por exemplo, que a presença de câmeras induz nos cidadãos um estado consciente e permanente de visibilidade que assegura o funcionamento automático do poder, quando pesquisas empíricas demonstram que em alguns casos os cidadãos não estão cientes da presença de câmeras em determinados espaços públicos. ${ }^{11}$ Da mesma forma, como a população que circula pelos espaços públicos não é predefinida como desviante e a identidade daqueles que estão sob vigilância é desconhecida, o resultado dos registros dos indivíduos anônimos não podem ser confrontados com um dossiê preestabelecido, logo o efeito de correção é praticamente inexistente.

Porém, se o panóptico pode e deve ser relativizado no caso de utilização de câmeras em espaços públicos, o panoptismo segue vivo. Em pesquisa empírica conduzida em relação ao sistema de câmeras de uma cidade do Espírito Santo (BRICALLI, 2015, p. 138-143), mostrou-se como a presença de câmeras atualiza e alimenta um estado permanente de controle a partir de uma rede de vigilância que se forma entre os cidadãos entrevistados, cujos alvos são os grupos sociais mais frágeis, os "indesejáveis", tais como os negros, os usuários de drogas, os bêbados, os moradores de rua e os vendedores ambulantes. Neste caso constitui-se a perfeição das disciplinas, quando cada indivíduo, mais do que elementos sobre os quais o poder deve atuar, são as próprias engrenagens do poder, fazendo-o circular de maneira que seja, simultaneamente, o mais econômico e eficaz possível.

Se por um lado a clássica imagem do panoptismo está atualizada na utilização de câmeras em espaços públicos, pois estas substituem o olhar dos guardas e vigias das sociedades disciplinares ao mesmo tempo em que induzem uma rede de controle sobre os excluídos da sociedade, representando uma vigilância constante e irrestrita, por outro, como elas não dependem do confinamento como técnica de poder, pois estão espalhadas inclusive

\footnotetext{
${ }^{11}$ A este respeito ver Bricalli (2015) e Bricalli e Zanotelli (2016) para o caso de uma cidade brasileira e Norris and Armstrong (1999, p. 92) para os casos de algumas cidades britânicas.
} 
em espaços abertos de circulação, isso nos aproxima do conceito das sociedades biopolíticas ou de segurança.

Inseridas num contexto de sociedade da segurança, as câmeras encerram um poder que não é aquele de causar a morte a partir de uma intervenção direta sobre o indivíduo, mas que se exerce fundamentalmente em positividade, o direito de causar vida a um conjunto de população que agora circula pela cidade supostamente com maior sensação de segurança ${ }^{12}$. Da mesma forma não se trata apenas de um poder ancorado na lei, que determina o permitido e o proibido, mas que opera distribuições em torno da norma, uma normalização característica de uma tecnologia de poder centrada na vida. Uma vida, é claro, que é a busca ilusória de um espaço o mais homogêneo possível, marcada pelo poder de exclusão, mesmo que simbólica, daqueles grupos de indivíduos que insistem em perturbar a pretendida ordem de uma sociedade que não suporta as diferenças. ${ }^{13}$

As câmeras de vigilância parecem ilustrar de maneira mais significativa a espacialidade das sociedades de segurança. Elas não dependem de uma reconstrução de um espaço já dado, mas de um aproveitamento dos dados de modo a maximizar os elementos positivos e minimizar os riscos e inconvenientes. Elas são instaladas sobre uma materialidade já existente (ruas, avenidas, praças) e obedecem a critérios já existentes (criminalidade, circulação de pessoas, entradas/saídas da cidade), assim como têm um aspecto de polifuncionalidade (registram crimes, acidentes de trânsito, circulação de pessoas) e trabalham com o futuro ("prevenção" de situações indesejáveis de ordens diversas, por exemplo).

As câmeras respondem por um problema da segurança, que para Foucault é um problema dos elementos que se deslocam, como as mercadorias, os veículos, as informações, as pessoas, os criminosos, etc. É preciso geri-los e controlá-los a partir de uma estimativa de probabilidades, pois o espaço da segurança remete a acontecimentos possíveis e aleatórios. As câmeras de vigilância nos interrogam a respeito da discrição de um poder que, exercido positivamente, estaria a serviço da paz, da política, da ordem, em nome da sobrevivência do conjunto da população. Para que seja efetivo, o poder necessita de um controle geral e irrestrito que inclui a população de uma maneira geral, cujos todos componentes são considerados, à priori, suspeitos, de modo a justificar sua política. Daí estarmos situados num tempo em que as fronteiras entre guerra e paz ou civil e militar, são cada vez menos nítidas, no qual se consagram expressões como militarização da questão urbana (SOUZA, 2008) e urbanismo militar (GRAHAM, 2011).

\section{Considerações finais}

À luz das contribuições das pesquisas de Michel Foucault sobre o poder e o espaço, propomos, neste texto, um exercício de análise da gestão dos riscos na sociedade atual, particularmente como as formas de exercício do poder se inscrevem no governo dos riscos nas cidades brasileiras contemporâneas. Distinguimos quatro destas formas que, acreditamos, são importantes manifestações dos poderes descritos por Foucault: i) a atuação da polícia militar

\footnotetext{
12 Isso, é claro, é parte do discurso que ajuda a sustentar a política de câmeras. Na prática, as pessoas não se sentem mais seguras com câmeras, tratadas inclusive com desprezo. Ver Bricalli (2015).

${ }^{13}$ Aqui podemos mencionar a utilização de câmeras como parte de projetos de gentrificação urbana de modo a valorizar determinados espaços da cidade tornando-os mais "seguros", por exemplo, para o consumo e para o turismo, a partir da exclusão de grupos sociais considerados indesejáveis, que "arranham" as imagens das cidades. Ver, a este respeito, Martinais e Bétin (2004) para o caso de Lyon, na França; Coleman e Sim (2002) e Coleman (2004) para o caso de Liverpool, Reino Unido; e Norris e Armstrong (1999) para o caso de outras cidades inglesas.
} 
sobre os espaços estigmatizados, onde vive a população pobre brasileira; ii) a política de encarceramento em massa levada a cabo pelo Estado brasileiro; iii) a expansão de condomínios fechados; iv) a utilização de câmeras de vigilância em espaços públicos.

A atuação da polícia militar brasileira e a política de encarceramento em massa do Estado brasileiro mostram que, particularmente no Brasil, o Estado soberano vive, malgrado a tendência de se acreditar nas formas mais sutis de controle na sociedade atual. De outro lado, a proliferação de espaços fechados de moradia, como são os condomínios fechados, demonstram como o governo da insegurança já não é exclusividade do Estado, pois são estratégias de acumulação de capital por parte de empresas privadas. Os condomínios misturam aspectos do poder disciplinar, pois são espaços artificiais ideais fechados construídos em meio às cidades, marcados pelos clássicos símbolos de controle, como os guardas, os muros e as cercas, mas possuem também aspectos do que Foucault denominou de biopolítica, pois são espaços que vendem "vida", a partir de um retorno mitificado à comunidade, à natureza, à segurança, longe da "morte" que são os considerados problemas urbanos.

Finalmente, as câmeras de vigilância destinadas ao controle dos espaços públicos, também misturam aspectos de disciplina e biopolítica. Os sistemas de câmeras, pelo menos formalmente, atualizam o panóptico de Foucault, na medida em que a presença física das câmeras e a sala de controle onde elas são operadas pode ser pensadas como a torre central e os cidadãos como os prisioneiros. Assim, as câmeras das cidades representam não mais a vigilância circunscrita a um espaço fechado, mas um panoptismo generalizável pelo espaço como um todo. Neste caso, as câmeras estão destinadas ao governo sobre um espaço aberto de circulação, como Foucault se referia às sociedades de segurança. As câmeras representam uma típica atuação da versão atualizada do Estado liberal, o neoliberalismo, no sentido de gestão da insegurança a partir de seus efeitos, para mostrar à população que algo está sendo feito em nome da segurança, pois governar as causas seria muito custoso e desinteressante do ponto de vista neoliberal.

Conclui-se afirmando a necessidade de pesquisas empíricas que mostrem tanto a atualidade quanto os limites da abordagem de Foucault sobre o poder e o espaço. O caso brasileiro pode ser ainda mais elucidativo tanto em um caso quanto no outro: ao mesmo tempo em que os problemas de insegurança de nossas cidades são dos mais complexos do mundo, logo o seu governo tende a mostrar diversas faces, o Brasil é um país que, embora tenha raízes na tradição moderna sobre a qual Foucault conduziu suas pesquisas, possui muitas particularidades que não admitem a transposição de ideias sem as devidas contextualizações para a sua própria realidade social.

\section{Referências}

AGAMBEM, G. Como a obsessão por segurança muda a democracia. Le monde diplomatique. São Paulo, ano 8, n. 78, janeiro de 2014.

BRICALLI, I.L. O paradoxo da cidade monitorada: vigilância limitada e espaços públicos fragilizados a partir do estudo do sistema de câmeras do município de Vila Velha - ES. 2015. 182f. Dissertação (Mestradoem Geografia) - Programa de PósGraduaçaoem Geografia,Universidade Federal do Espírito Santo, Vitória, 2015.

BRICALLI, I. L.; ZANOTELLI, C. L. A fragilização dos espaços públicos a partir da utilização de câmeras de vigilância na cidade de vila velha (ES). Revista Geo UERJ, n. 29, p. 133-169, 2016. 
CALDEIRA, T. P. R. Cidade de Muros. Crime, segregação e cidadania em São Paulo. São Paulo: Editora 34/Edusp, 2000.

COLEMAN, R. Reclaiming the Streets: Closed Circuit Television, Neoliberalism and the Mystification of Social Divisions in Liverpool, UK, Surveillance and Society, 2(2/3): 293309, 2004.

COLEMAN, R.; SIM, J. 'You'll never walk alone': CCTV surveillance, order and neoliberal rule in Liverpool city centre, British Journal of Sociology, 51(4): 623-639, 2002.

DELEUZE, G. Post-scriptum sobre as sociedades de controle. In: Conversações. São Paulo: Editora 34, 2007. Cap. V, p. 219-226.

Foucault. São Paulo: Brasiliense, 2005.

FOUCAULT, M. História da Sexualidade: a vontade de saber. 6 ed. Rio de Janeiro: Graal, 1988.

Sobre a geografia. In: Microfísica do poder. Rio de Janeiro: Graal, 2008a. Cap. X, p. 153-168.

. O olho do poder. In: Microfísica do poder. Rio de Janeiro: Graal, 2008b. Cap. XIV, p. 209-228.

Nascimento da biopolítica. São Paulo: Martins Fontes, 2008c.

. Segurança, Território, População. São Paulo: Martins Fontes, 2008d.

. Vigiar e punir. História da violência nas prisões. 36. ed. Petrópolis: Vozes, 2009.

GARLAND, D. A cultura do controle: crime e ordem social na sociedade contemporânea. Rio de Janeiro: Editora Revan, 2008.

GRAHAM, S. Cities under siege. The new military urbanism. New York: Verso, 2011.

HAESBAERT, R. E Foucault continua provocando os geógrafos... Resenha FOUCAULT, Michel. Segurança, Território, População. São Paulo: Martins Fontes, 2008. GEOgraphia, vol.10, n. 19, 2008.

Territórios, in-segurança e risco em tempo de contenção territorial. In: Póvoa Neto, H., Ferreira, A. Vainer, C., Santos M. (orgs). A experiência migrante: entre deslocamentos e reconstruções. Rio de Janeiro: Garamond. 2010., p. 537-557.

MARTINAIS, E.; BÉTIN, C. Social aspects of CCTV in France: the case of the city of Lyons. Surveillanceand Society, vol. 2, n. 2-3, p. 361-375, 2004.

NORRIS, C.; ARMSTRONG, G.The Maximum Surveillance Society:The Rise of CCTV. Oxford: Berg, 1999. 
SANTOS, M. A natureza do espaço. Técnica e tempo, razão e emoção. 4. ed. São Paulo: Edusp, 2008.

SOARES, L. E. Desmilitarização e reforma do modelo policial. Le monde diplomatique. São Paulo, ano 7, n. 76, p. 18-19, novembro de 2013.

SOJA, E. W. Postmetrópolis. Estudios críticos sobre lasciudades y lasregiones. Madrid: Traficantes de sueños, 2008.

SOUZA, M. L.Fobópole. O medo generalizado e a militarização da questão urbana. Rio de Janeiro: Bertrand Brasil, 2008.

WACQUANT, L. Prisões da miséria. Rio de Janeiro: Jorge Zahar, 2001.

ZANOTELLI, C. L.; MEDINA, J. L. B.Análise dos discursos sobre a criminalidade e a delinquência nos jornais A Gazeta, Notícia Agora e A Tribuna e seus efeitos sobre a política de segurança e a percepepção social de (in) segurança. Relatório de pesquisa. Secretaria de Segurança Urbana de Prefeitura Municipal de Vitória, fevereiro de 2008.

ZANOTELli et. al. Atlas da criminalidade no Espírito Santo. Annablume, Fapes, São Paulo, 2011. 